\section{University News:}

Bradford

DR M. G. MYLRoI, at present division instrument manager of ICI Fibres, Ltd., has been appointed to the chair of control engineering.

Newcastle upon Tyne

Dr E. J. Field has been appointed to a personal chair in experimental neuro-pathology.

Sheffield

THE following appointments have been made: $\mathbf{M r} \mathbf{H}$. Nicholson, at present lecturer in the Department of Engineering in the University of Cambridge, to the chair of control engineering in the Department of Electronic and Electrical Engineering; Dr F. A. Benson, at present reader in electronics in the university, to the chair of electronic and electrical engineering; Dr B. B. Argent, at present reader in metallurgy in the university, to the newly established third chair of metallurgy; Dr D. S. Munro, at present reader in clinical endocrinology in the university, to a personal chair of clinical endocrinology in the Department of Pharmacology and Therapeutics.

\section{Appointments}

DR A. KELLY has been appointed superintendent of the National Physical Laboratory's newly organized Division of Inorganic and Metallic Structures.

Frederic M. Philips has been appointed director of the Office of Public Affairs of the Smithsonian Institution.

THE following appointments have been made in the Office of Scientific Personnel of the US National Research Council: Dr W. C. Kelly has been appointed director of the office in succession to Dr M. H. Trytten; J. C. Boyce will continue to have the responsibility of deputy director and has been given the additional title of director of associateships; Dr E. W. Scott has been appointed director of special international programmes in succession to S. S. Steinberg.

Corrigendum. In Table 1 of the article "Transplantable Mouse Neoplasm Control by Neutron Capture Therapy", by Lee E. Farr and T. Konikowski (Nature, 215, 550; 1967), the heading of the first column should read "Neutron flux $\mathrm{cm}^{2} \times 10^{12}$ ",

Erratum. In the communication entitled "Photochemical Oxidation of Neptunium(V) by Xenon Trioxide" (Nature, $215,732 ; 1967)$ the first sentence of the second paragraph should read: "The neptunium(V) was prepared by solution of neptunium dioxide in concentrated perchloric acid and reduction of the resulting neptunium(VI) to neptunium(V) with hydrogen peroxide". The third sentence of the same paragraph should read: "The ionic strength was maintained constant at 2 molar with lithium perchlorate which was recrystallized six times before use". Reference 2 should be to Koch and Williamson, not Koch and Williams, and reference 4 should be to Cleveland, J. M., Inorg. Chem., 6, 1302 (1967). The spectrophotometer used was GE No. PH/18A/T10P-6V (CPR).

\section{CORRESPONDENCE}

\section{Voyager Experiments}

Sir,--In 1973 the National Aeronautics and Space Administration proposes to conduct the first of the Voyager series of missions to Mars, using the Saturn launch vehicle. We wish to call the attention of the scientific community to the opportunity of proposing experiments for this initial flight.

The primary objectives of the 1973 Voyager Mars mission are to obtain information relevant to the existence and nature of extraterrestrial life; the atmospheric, surface and body characteristics of the planet; and the planetary environment. Orbital reconnaissance, direct measurements during atmospheric entry, and investigations after soft-landing on the Martian surface are part of the mission.

As you may know, funding for the Voyager Program is under formal consideration at the present time by the US Congress, and final funding authority has not yet been obtained for proceeding with Voyager in Fiscal Year 1968. Regardless of the level of funding support obtained for Voyager this fiscal year, it is our plan to begin evaluating scientific proposals on November 1, 1967, and to select scientists for participation in the planning and development steps by February 1968.

Approximately 5,000 copies of the formal announcement have been mailed to scientists on August 9, 1967. If others are interested, additional copies may be obtained from Dr Robert F. Fellows, Code SY, Voyager Program Scientist, NASA Headquarters, Washington, D.C. 20546. Yours faithfully, Homer E. Newell

Associate Administrator for Space Science and Applications.

\title{
THE NIGHT SKY IN SEPTEMBER
}

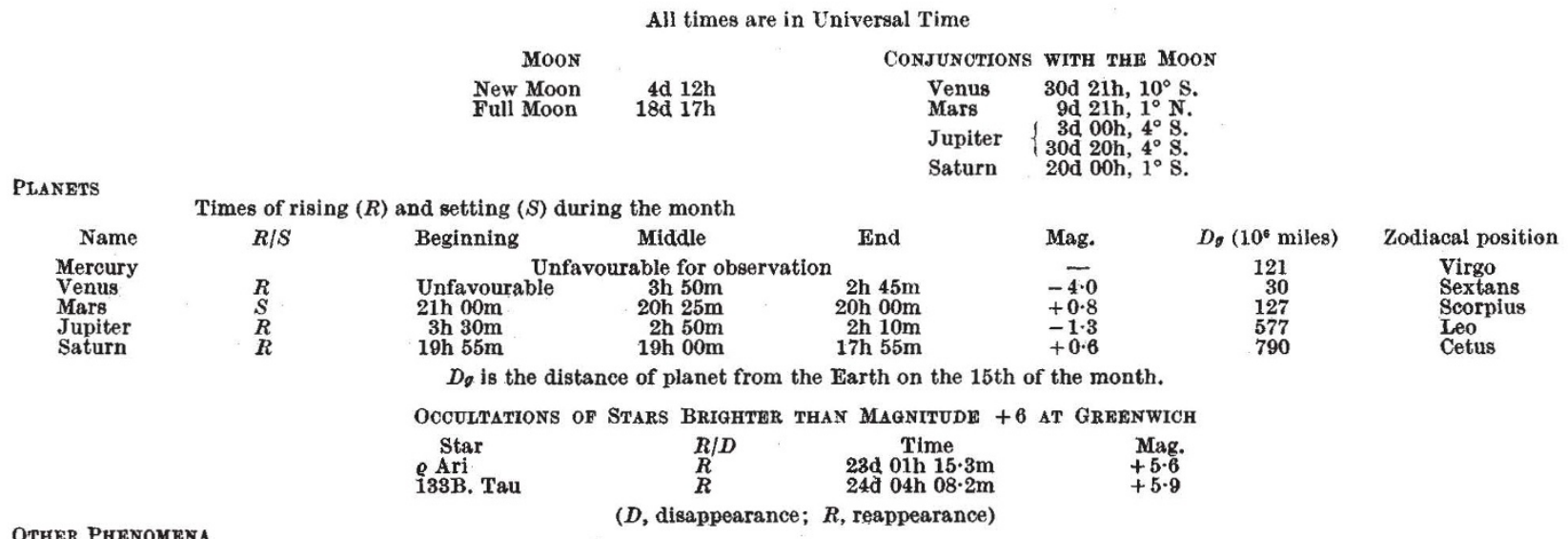

THER PHenOMRNA

$4 d 00 \mathrm{~h}$, Venus $10^{\circ} \mathrm{S}$. of Regulus.

9d 21h, Mars occulted by the Moon, visible in Antarctica.

$10 \mathrm{~d} 12 \mathrm{~h}$, Antares occulted by the Moon, visible N. Asia.

$2 \theta d 00 \mathrm{~h}$, Saturn occulted by the Moon, visible Greenland, Iceland.

$23 \mathrm{~d} 07 \mathrm{~h}$, Mars $3^{\circ} \mathrm{N}$. of Antares.

23d 18h, Equinox. 